\title{
RISK ACCORDING TO THE RELATIONAL THEORY OF SOCIETY
}

\author{
Emiliana Mangone \\ University of Salerno
}

\section{/// Risk As a Symbolic-Cultural Reality: A Theoretical Overview}

When talking about risk, we usually refer to situations affecting individuals. However, a more detailed analysis shows that, in everyday life, risk is actually closely linked to social and cultural aspects of existence (Douglas \& Wildavsky 1983). The latter dimension in particular is often overlooked in risk studies: it is not considered a problematic aspect of society but rather an "accident" in the regular course of social events.

There is no unequivocal definition of risk, nor is there a single approach to analysing it (Barbieri \& Mangone 2015). Several disciplines have dealt with this issue, each basing its contribution on its own theoretical foundations. On deciding to study the concept of "risk," three authors come to the mind of researchers, and especially of sociologists: Luhmann (1991), Beck (1986), and Giddens (1990). To the names of these scholars, whose approaches are more focused on socio-cultural dimensions and context, the name of Douglas (Douglas \& Wildavsky 1983) can also be added. These are reputed to be the key authors for the development of the analysis of this concept.

The various definitions coined over the last few decades have not managed to make the concept clear, and it still remains very ambiguous. On the one hand, people are attracted by risk or even fascinated by it; on the other hand, they are wary and feel fear. One reason is that this concept is highly dependent: two features stand out - the influence of culture and context on risk, and its inextricable ties with other concepts (uncertainty, confidence, security, modernity, globalization, etc.). This indissoluble bond with other concepts underpins the reflections of contemporary sociologists on 
this theme, starting with Luhmann (1991), who compellingly links risk to the ideas of probability and uncertainty, and differentiates it from the concept of danger. It is not possible to talk about risk when the result of an act is certain. Therefore, primitive cultures had no knowledge of this concept. Hence the idea of risk is typical of modernity and should not be confused with hazard or peril. Rather, it indicates risky choices that are actively pursued in view of future possibilities (Giddens 1990). Obviously, what is considered risky (behaviour, practices, environments, etc.) depends on what Beck (1986) called "relations of definitions." This means that every society, at a given time, determines its risk hierarchy; however, the perceptions underpinning the construction of that hierarchy do not always correspond to objectively measurable risks, nor are they generated by individual decisions. This is mainly because the attention of the public, due to the influence of mass media and the overall increase in wealth, has shifted toward needs related to the quality of life. A step of this nature indicates the reciprocity between the life-world and the social system and represents a step in which the individual is considered as a "subject" in relational processes (Donati \& Archer 2015). We thus shift from an approach reducing risk to its mere economic aspects to one considering the overall interactions between these and other important social and cultural variables.

In such a complex scenario as contemporary society, where relations (at different levels) play a dominant role in social phenomena, and therefore also in the social construal of risk-meaning the way in which people perceive, understand, and interpret the world around them (Douglas 1997) it is necessary to distinguish the various sociological dimensions of analysis (Collins 1988). The first one is the macro dimension, pertaining to social systems and their organization forms; in this case, the object of study is the structure and its systems. The second dimension is the micro one, dealing with the relationship between individual and society and with social actions; in this case, the person and his action are the object of study. Finally, there is the meso dimension, focused on relationships between the social system and life-world, where the latter is understood as the set of meanings and representations of culture. It is this dimension that will henceforth characterize the path we are about to describe.

From what has been said thus far, it is easy to understand how the concept of risk has changed (and is still changing) in contemporary society, following the latter's transformations. The transition from local to global has generated the idea of "global risks," which in turn has prompted the statement that this is a "risk society" (Beck 1986). We have thus adopted 
the idea that risk factors are no longer hidden only in nature, but also in humans, in their behaviours, their freedom, their relations, their association, and in society (Ewald 1993). In the following pages, our attention will be focused on two key elements of everyday life that must be considered when dealing with processes of constructing, identifying, and selecting risks: culture and social relations. Supported by meso-range theories which were developed in recent decades and which studied the relations between the social system and life-world, we will try to describe the links between risk, culture, and social relations.

Broadly speaking, culture should be understood as "the expression of the totality of man's social life. It is characterized by its collective dimension. In the end, culture is acquired and therefore does not depend on biological heredity. However, although culture is acquired, its origin and its characteristics are predominantly unconscious" (Cuche 1996: 16). In other words, culture is constituted by both objective elements (tools, capabilities, etc.) and subjective ones (beliefs, roles, values, etc.) and it represents one of the principal factors when evaluating individuals' sense of belonging to a society. All activities and institutions are "cultural," because they require meanings in order to operate. With the above, we are not backing the idea that social life is connected to cultural determinism. Rather, we support the claim that culture is the key component for individual actions: "every social practice depends on and relates to meaning; consequently, that culture is one of the constitutive conditions of existence of that practice, that every social practice has a cultural dimension" (Hall 1997: 225-226). Cultural objects have meaning among the people living in a given social world and the latter, in turn, has meaning only by way of the culture (Griswold 1994) through which it is observed.

Culture, therefore, is a fundamental dimension of everyday life and as such it is necessary to understand it in relation to the various situations of the social world, including those defined as "risky." In this way, we can theorize new paths aimed at improving the relations and forms deriving from culture, through which we express the interactions between people as well as between people and other elements of the system.

This interpretation of the relationship between risk and culture draws a complex scenario, in which the world and the people in it constitute an endless web of relationships based on events that intersect, overlap, and influence each other-and that can also often be discordant (Festinger 1962). The everyday sequence of events, through definition and elaboration, allows for the reproduction of "meaning" through "symbolic mediation," 
which favours the interpretation and, more importantly, the very construction of reality. Social reality - and, therefore, also the construction, identification, and selection of risk-stems not only from the social meanings attributed to a certain phenomenon (cultural object) but also from the products of the subjective world of people. People's patterns of action and relationships are built according to the meaning that they attribute to daily existence. In other words, individuals are faced with a world of meanings and events that become real for them as conscious and perceiving "social beings."

Risk is therefore a reality for people, deriving from the relations that people establish with others and that are manifested through their everyday roles. In general, risk can be considered a social problem because it is a relationship between "fact" and "structure"; it is the result of interpretation and therefore it is a cultural object. And precisely because risk is interpreted as a culturally defined social problem, over time we witness an increase or decrease in its shared forms of representation. In such a scenario, risk representations express both the subjective sense attributed to this category and the cultural and social framework of reference available in a given time and space (Schütz 1932): construction and representations of risk exist both in the micro-everyday scene and in the macro-institutional one.

On these premises Mary Douglas (1985) argues that culture is a "mnemonic system" that helps people in the calculation of risk and consequences, and shifts the focus from the idea of individual risk to that of collective risk. Of course, Douglas's cultural theory of risk should be seen in the broader context of her studies on primitive thought and taboos (Douglas 1966), some of which she links with modern human behaviour in risky and dangerous situations. This interpretation is based on the principle that in every place and age the universe is interpreted in moral and political terms (Douglas 1992) and the concept of risk becomes of paramount importance in this sense. In modern societies, however, risk does not perform the same function as danger in pre-modern ones. Contemporary societies typically replace "sin" with "risk," because globalization has helped to establish cultural systems that are able to integrate ever larger communities-whose vulnerability, however, has increased precisely because they have become "world systems." Douglas's cultural-symbolic analysis is not limited to an attempt to explain the influence of culture on the concept of risk: in her book Risk and Culture, co-authored with political scientist Aaron Wildavsky (Douglas \& Wildavsky 1983), she also deals with the issue of knowledge, 
particularly by highlighting the fact that knowledge of risk(s) is never exhaustive. ${ }^{1}$

Although it appears static, the cultural-symbolic approach allows us to define, through general cultural theory, the conceptual boundaries (Tansey \& O'Riordan 1999) within which we can then review and redefine processes of social construal. By doing so, we can add new tiles to the mosaic describing and interpreting the reality of the social dynamics connected with risk. However, the four issues raised by Douglas (1992) as the starting point for a comparative study of risk perception remain of primary importance. These are: (a) the influence of risk on the goals of the person perceiving it; (b) whether the original community is part (integral or not) of the person's goals; (c) understanding the influence on the individual or collective good of the risk depending on the type of community; and finally, (d) classifying various communities on the basis of the support, commitment, organization, and boundaries defined by their members.

In summary, we can state that the cultural approach helps us to understand non-experts' perception of risk by offering a systematic view of the range of objectives that an individual may try to reach. In other words, risk should not be considered a technical problem but rather a problem of everyday life involving political implications and people's positions in relation to both individual and collective objectives.

\section{/// Risk According to the Relational Theory of Society}

We can intuitively appreciate how people's attitudes and actions in regard to risk are influenced, on the one hand, by culture and, on the other, by an indissoluble link with context and everyday life. In doing so, we pay attention to the "person" not only as an entity performing an action, but as a "subject" and active part of social processes. Consequently, it is possible to transition from an approach to social phenomena aimed at searching for a cause (causality) to one focusing on the overall interaction between individual, social, and environmental variables (relationality). In this paper, starting from Archer's morphogenesis cycle (1995), we will examine risk from the perspective of relational sociology or the "relational theory of society" (Donati 1991, 1993, 2011a), i.e., by reading social risk in a way that considers social relations to be the starting point (Terenzi et al. 2016).

1 The scholar highlights four risk-related issues emerging from the interplay between the degree of knowledge (certain/uncertain) and consensus (complete/contested). 
We have chosen to commence our discussion of risk from the relational perspective with Archer's morphogenesis cycle (1995) because Archer was perhaps the first scholar who, despite some criticism, strongly advocated the overcoming of certain strong dichotomies that had existed throughout the history of sociology and that had developed further in relational socio$\operatorname{logy}$ (individualism/holism, structure/agency, micro/macro). The author claimed that several factors and levels co-exist simultaneously in the process of defining the goals actualized by social systems. Archer argued that

the crucial linkage to make and to maintain is not between the "micro" and the "macro," conceived of as the small and interpersonal in contrast to the large and impersonal, but rather between the "social" and the "systemic." In other words, systemic proprieties are always the ("micro") context confronted by ("macro") social interaction, whilst social activities between people ("micro") represent the environment in which the ("macro") features of systems are either reproduced or transformed (...) Two implications follow from this. Firstly, that the central theoretical task is one of linking two qualitatively different aspects of society (the "social" and the "systemic," or if preferred "action" and its "environment") rather than two quantitatively different features, the big and the small or macro and micro. (...) The second implication is that if the misleading preoccupation with size is abandoned, then the linkages which need forging to account for the vexatious fact of society are those between the "people" and the "parts" of social reality (Archer 1995: 11-12).

In this way, the relationship between individual and society assumes a multidimensional connotation that is highlighted in the morphogenetic cycle, ${ }^{2}$ macro stems from micro, and conditions it by retro-acting on it. The two elements cannot be studied separately, nor can one be given precedence over the other, since structure and action are different levels of a stratified social reality, each with specific and non-reducible characteristics. In morphogenesis, processes depend on the interaction with the lifeworld. Society must therefore be studied as it is, rather than as we would like it to be. Starting from the assumption that cultural systems result from human action and that, once they reach their autonomy, they influence

2 The morphogenetic cycle, in its general form, is characterized by social conditioning, by sociocultural interaction, and by structural elaboration. 
future generations, we emphasize the importance (within the morphogenetic cycle) of the interactions between subjects, who are interconnected by both cultural conditioning (the structural setting of the cultural system) and the resulting elaboration. The latter may be oriented toward either confirmation (reproduction) or change (innovation). This shows that the results of a process - in the present case, the results of a faced risk-can lead to expected or unexpected outcomes, and that interaction processes, proceeding in several directions, similarly produce emerging effects in several directions. Applying this multidimensional approach to risk means observing both institutions and people-but above all the relations between them-and overcoming the traditional views that separated these levels as well as the various elements involved in the processes of the social construal of risk.

Risk studies should therefore combine systems (the objective dimension) and people (the subjective dimension). In other words, they should be able to combine objective aspects with subjective ones, taking into account all the dimensions, levels, and factors involved in the social process of construction, identification, and selection of risks. These processes are knowledge-oriented work that is not limited to implementing actions: it is not imperative to represent a risk, to know it, to make hypotheses and speculate, to redirect the course of action en route, because the relationship with reality is never given and at all times new possibilities may open up and ask for exploration. These definitions and reflections on risk prompt us to state that its analysis should take into account its characteristic multidimensional and multifactorial nature. In this way, we pay more attention to the sphere of social relations within the processes that develop in society. Those regarding risk are included in this trend, since all social phenomena, attitudes, behaviours, and actions concerning them are built in an area that has its own places, times, and symbols, which are fundamental for the cognitive processes of self-active signification implemented by individuals for the construction of social reality in their daily life experience.

For this reason, we propose the relational perspective (Donati 1991, 1993, 2011a) as an additional key to understanding the concept of risk. Indeed, social relations are not a constraint for the person, but rather the main element advancing the subject's self-determination based on reflexivity (Donati 2011b). Taking social relations into account allows us to consider both life-world and social system. The relation should be intended as an emergent phenomenon (generative semantics) of a mutual act (rela[c] tion) with an autonomous connotation that goes beyond those who imple- 
ment it, but that at the same time is due to referential semantics (refero). It is embodied within a framework of symbolic meanings (culture) as well as structural semantics (religo), given that it is at the same time both a resource and constraint for the social system.

These are the general foundations of the relational theory of society. According to this perspective, risk, intended as a descriptive model, has some distinguishing features. For example, as a dimension of everyday life, it is a "neutral category" (Donati 1990), because it is based on Bauman's (1999) "insecure security." The positive or negative outcomes of this "insecure security" will depend on the kind of balance established between "resources and challenges" (Carrà 1992) or, in other words, between "goals and means." To elucidate our arguments, we will apply to risk what Merton (1968) said about anomie: risk is a "normal" fact, a consequence of the pressures exerted by social structures over their members. If we consider the two elements that form social systems in Merton's theory, we can better understand the origin and direction of these pressures: the first is the cultural structure, the second is the social structure, formed by statuses and their role functions. Both these structures have institutionalized values: the "goals," which are nothing more than the objectives, aspirations, and interests of the members of society, organized in a priority scale characterizing the social system of reference; and the "means" or rules, which determine how to achieve the goals. Goals and rules do not always have the same emphasis, much less a constant relationship, despite the efforts by social institutions to maintain a balance between these two institutionalized values.

In this situation, people obviously adopt individual adaptation schemes (Merton proposes a typology), which vary according to their position in the social structure-social status is the element on which the possibility of reaching a goal by legitimate means is based. This suggests that the potential for a risky situation is inversely proportional to the legitimate opportunities of reaching the proposed goal. Adjustment takes different forms depending on how the contradiction between the "goals" set by the culture and the "means" employed to achieve them is resolved. Borrowing the terminology of cultural-symbolic theory, we can talk about a contradiction between knowledge (certain/uncertain) and consensus (complete/ disputed).

In other words, being in a risky situation means testing the limits of our knowledge and skills, the difficulty in finding "meaning" in what happens, and the feeling that the choice is a leap in the dark anyway, as it is basically impossible to untangle its elements (Carrà et al. 2006). Donati (1990) 
suggests breaking risky situations down into three main areas: the area of needs, corresponding to "challenges" or "goals," where all that concerns their satisfaction is related to "resources" or "means." Within this area, we must distinguish material and primary goals from secondary and relational ones: for the former, resources or means are well defined, while for the latter there may be several combinations given the many elements involved. The second area, that of transaction, is characterized by the presence of an "exchange situation" between people through their relations and the deployment of the mutual expectations of demand and response capability. Finally, the transition area includes all those situations that are particularly important for people's lives; every transition is a goal to be achieved by leveraging the resources of the primary network of relationships in order to find a new balance.

\section{/// A Model for Reading Social Risk Through a Relational Lens}

Based on the above theoretical foundations, we offer a key to understanding social phenomena and risk by focusing our attention on the interplay of social relationships that people weave into their everyday life, starting from their primary group of belonging. Since taking a risk means not only finding a balanced combination between "goals" and "means," but also selecting both "goals" and "means," this also allows people to plan actions promoting the achievement of this very balance.

We will now advance some observations to help outline what we have argued to this point. First of all, in contemporary society, risk-separated from the elements that used to connect it solely to nature-assumes a central role in peoples' daily lives and in their subjectivity, as well as in the policy agendas of many nations. Despite this centrality, however, neither people nor institutions show an active response capacity (reflection) to situations producing anxiety and fear. When dealing with risky situations, people seldom adopt a pro-active position, preferring a re-active one. This also applies to political institutions, which often find themselves responding to emergency situations rather than seeking to avoid and/or prevent such situations. This is a common propensity in situations characterized by little or no communication and by an absence or scarcity of social relations networks. Indeed, these networks are precisely what kindle the reflexivity processes that in turn allow for conscious and responsible decisions.

In proposing an interpretation of risk, we should therefore adopt a model (Fig. 1) derived from the relational approach but also containing 


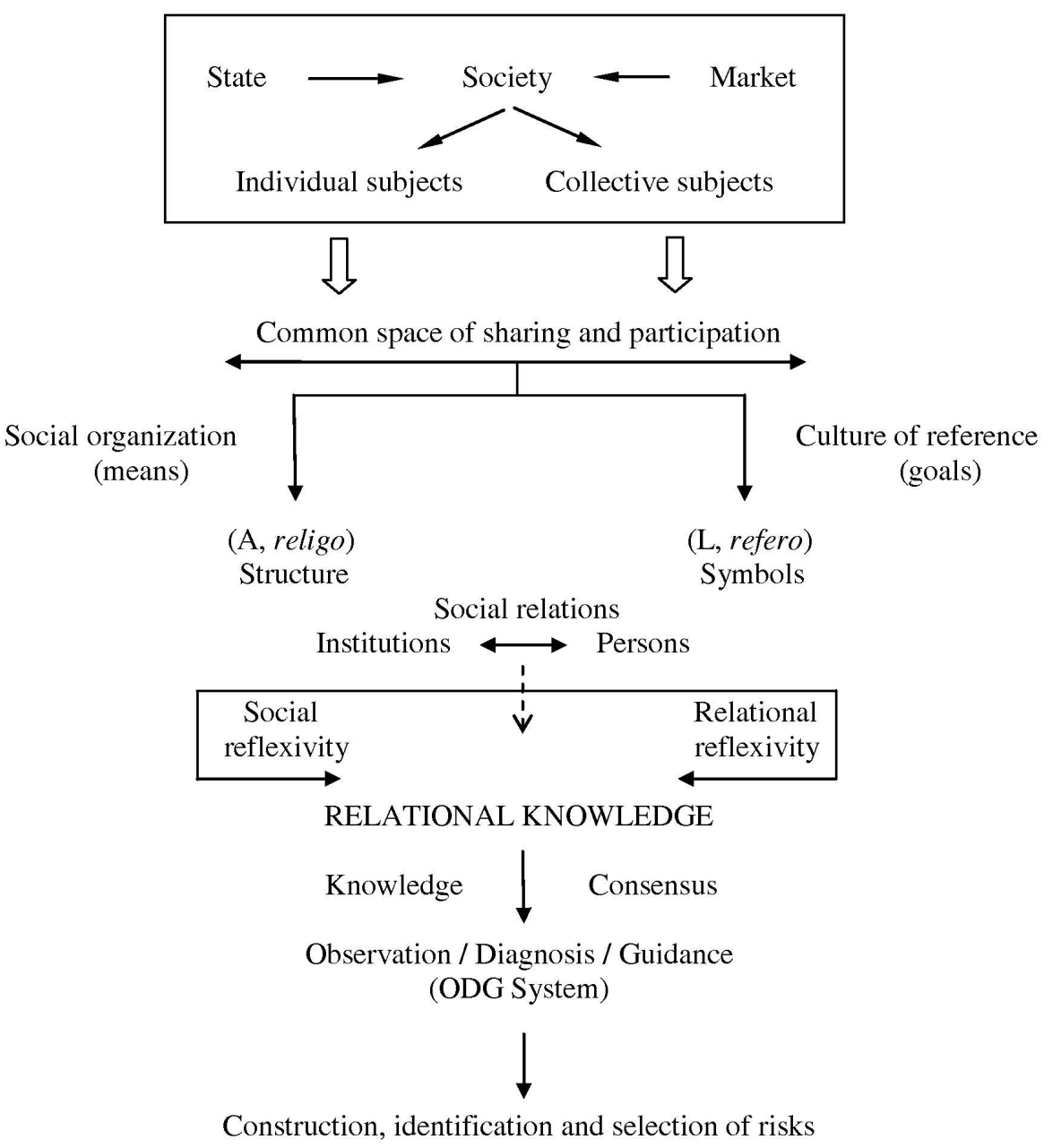

Figure 1. Interpretation of risk based on the relational approach.

elements of the cultural-symbolic approach. Use of the relational theory of society is due to its specific quality of connecting real life and the social system, which promotes the interaction between institutions and individuals, because it is based on a communicative process implementing knowledge and consent. This reflection is typical of relations, and it is what Donati (2011c) calls "social reflection," i.e., the reflection (neither subjective nor structural) correlated to the order of reality of social relations. However, social reflexivity is not enough to produce "relational knowledge"- the knowledge concerning what one does, thinks, and experiences in a rela- 
tional context that emerges from the interaction between individuals' specific forms of acting and being (Mangone 2013), in this case, apropos of risk.

For "relational knowledge" to emerge from the interaction between the deciding parties (institutions/people), social reflexivity must become relational reflexivity ${ }^{3}$ (Donati 2011b, 2011c). Reflexivity processes (both social and relational) thus promote the creation of "relational knowledge," i.e., a shared knowledge and consensus that directs the processes of construction, identification, and selection of risks by basing them on the relational observation-diagnosis-guidance system-ODG system (Donati 1991). This system can produce: (a) an observation that acknowledges the interaction between the "creators" and the "receivers" (Griswold 1994) of risk as a cultural object; (b) a diagnosis that distinguishes risk as a social problem from its possible resolution; (c) a method of intervention on and in the context where risk as a social problem is generated before spreading to the entire system.

In order to make this model easier to understand and in order not to restrict it to being a mere graphic and descriptive exercise, we will now advance two examples: one concerns a health risk and the other an environmental risk.

The first concerns the construction, identification, and selection of health risks associated (or not) with vaccines. The current debate on the use or non-use of vaccines by people in countries where such practice is not mandatory (Haverkate et al. 2012) is indeed quite intense. In this example, vaccines are a means of reaching the goal, which is people's health (wellbeing). Applying the proposed model would lead us to the construction, identification, and selection of the health risk connected with the "non-use of vaccines" and hence the following choice of actions. This is easy to explain: between healthcare institutions-or their representatives, such as family physicians — and people, an "emergent effect" develops. It is a "relational knowledge" consisting of shared knowledge constructed precisely by the relationship between the experts (doctors) and the non-specialists. The construction of this knowledge is achieved through the ODG system: (a) epidemiological and statistical evidence is collected on the use of vaccines and the incidence of certain pathologies (observation); (b) analysis of

\footnotetext{
3 Relational reflexivity means that "the subjects orient themselves in the reality emerging from their interactions by taking into consideration the way in which said reality (by virtue of its own powers) can redound on the same subjects (agents/actors), since it surpasses their personal and aggregated powers" (Donati 2011c: 31).
} 
the evidence shows that non-use of vaccines results in an epidemic increase in already eradicated diseases such as measles (diagnosis); and (c) information campaigns are implemented not only for the expansion of knowledge about the risk of vaccinating versus not vaccinating one's children, but also for building the necessary consensus for the promotion of positive and responsible actions for the promotion and safeguarding of people's health (intervention-guidance).

The second example concerns the environmental risk associated with the use of pesticides. This example differs from the previous one not only in its scope but also because the process of constructing "relational knowledge" is more complex, given the multiplicity of relationships involved. This is because the institutions concerned are represented by two parties-government that is responsible for the welfare of present and future generations, and farmers' associations, which are safeguarding their own economic interests - while the people are represented by the totality of consumers. In addition, there is no single means or end: pesticides are the means to guarantee or increase crop yields (from cereals to vegetables), which is the farmers' goal, but to this we must add the governments' goal of protecting the health of the population by means of economic policies.

Through the ODG system, the use of pesticides is identified and selected as an environmental hazard (Lerche \& Glaesser 2006). In reaching this definition, the "relational knowledge" produced is the result of a balance between farmers' goals (profit) and governments' goals (public health) through greater reflexivity coming from and involving all the parties involved: (a) collection of data on the effects of agricultural pesticide use on the land and on consumers, and collection of data concerning agricultural production (observation); (b) analysis and interpretation of data, showing the emergence of pathologies in consumers, pro-aggressive soil pollution, and the extinction of some seeds, but also a lack of profit if the quantity of harvested products is reduced (diagnosis); and (c) implementation of economic policies and incentives supporting organic farming to ensure the profitability of farming, but at the same time to ensure the protection of the population's health-a balance between farmers' and governments' goals (intervention-guidance).

Finally, we emphasize that what we proposed here was a model for interpreting the dynamics of the social construal or collective construct of risk, overcoming the economic and probabilistic approaches that have always characterized the study of this phenomenon. However, this is possible only when the application of the ODG system (relational observation/ 
diagnosis/guidance) goes hand in hand with the idea that people's intervention can be determining (doing something!) and responsible (choice and blame attribution). In other words, in order to avoid an excessively rigid interpretation model, there must be a structure that guarantees accountability, evidence-based practice, and long-term action to achieve the balance between "goals" and "means." These are fundamental issues, as the "relational knowledge" of people that is generated through social relations is fundamentally based on the trust and consensus that the community, as opposed to the political system, can still claim to have within itself.

Bibliography:

/// Archer M.S. 1995. Realist Social Theory: the Morphogenetic Approach, Cambridge University Press.

/// Barbieri A.S.A., Mangone E. 2015. Il rischio tra fascinazione e precauzione, FrancoAngeli.

/// Bauman Z. 1999. In Search of Politics, Polity Press.

/// Beck U. 1986. Risikogesellschaft. Auf dem Weg in eine andere Moderne, Suhrkamp.

/// Carrà E. 1992. "Rischio": analisi di un concetto sociologico, "Studi di Sociologia”, vol. 30(1), pp. 47-59.

/// Carrà Mittini E., Santoro M. 2006. "Rischio", [in:] Sociologia della cultura, eds. S. Belardinelli, L. Allodi, FrancoAngeli, pp.193-210.

/// Collins R. 1988. Theoretical Sociology, Harcourt Brace Jovanovich.

/// Cuche D. 1996. La notion de culture dans les sciences sociales, La Découverte.

/// Donati P. 1990. Famiglia e infanzia in una società rischiosa. Come leggere e affrontare il senso del rischio, "Marginalità e società", vol. 14, pp. 7-38.

/// Donati P. 1991. Teoria relazionale della società, FrancoAngeli.

/// Donati P. 1993. Introdurione alla sociologia relazionale, FrancoAngeli.

/// Donati P. 2011a. Relational Sociology: A New Paradigm for the Social Sciences, Routledge. 
/// Donati P. 2011b. Modernization and Relational Reflexivity, "International Review of Sociology - Revue Internationale de Sociologie", vol. 21(1), pp. 21-39, doi: 10.1080/03906701.2011.544178, accessed 28.07.2017.

/// Donati P. 2011c. Sociologia della riflessività. Come si entra nel dopo-moderno, il Mulino.

/// Donati P., Archer M. 2015. The Relational Subject, Cambridge University Press.

/// Douglas M. 1966. Purity and Danger: An Analysis of Concepts of Pollution and Taboo, Penguin Books.

/// Douglas M. 1985. Risk Acceptability According to the Social Sciences, Russel Sage Foundation.

/// Douglas M. 1992. Risk and Blame: Essays in Cultural Theory, Routledge.

/// Douglas M. 1997. The Depoliticisation of Risk, [in:] Culture Matters: Essays in Honor of Aaron Wildavsky, eds. R.J. Ellis, M. Thompson, Westview, pp. 121-132.

/// Douglas M., Wildavsky A. 1983. Risk and Culture: An Essay on the Selection of Technological and Environmental Dangers, University of California Press.

/// Ewald F. 1993. Two Infinities of Risk, [in:] The Politics of Everyday Fear, ed. B. Massumi, University of Minnesota Press, pp. 221-228.

/// Festinger L. 1962. A Theory of Cognitive Dissonance, Stanford University Press.

/// Giddens A. 1990. The Consequences of Modernity, Stanford University Press.

/// Griswold W. 1994. Cultures and Societies in a Changing World, Pine Forge Press.

/// Hall S. 1997. The Centrality of Culture: Notes on the Cultural Revolutions of Our Time, [in:] Media and Cultural Regulation, ed. K. Thompson, Sage Publications, pp. 207-238.

/// Haverkate M., D’Ancona F., Giambi C., Johansen K., Lopalco P.L., Cozza V., Appelgren E., on behalf of the VENICE project gatekeepers and contact points. 2012. Mandatory and Recommended Vaccination in the EU, Iceland and Norway: Results of the VENICE 2010 Survey on the Ways of Implementing National Vaccination Programmes, "Euro Surveillance", vol. 17(22), pp. 1-6. 
/// Lerche I., Glaesser W. 2006. Environmental Risk Assessment: Quantitative Measures, Anthropogenic Influences, Human Impact, Springer.

/// Luhmann N. 1991. Soziologie des Risikos, de Gruyter.

/// Lupton D. 1999. Risk, Routledge.

/// Mangone E. 2013. La professione medica tra "essere", "fare" e "sapere relazionale", "Sociologia e Politiche Sociali”, vol. 16(2), pp. 163-180.

/// Merton R.K. 1968. Social Theory and Social Structure, Free Press.

/// Schütz A. 1932. Der Sinnhafte Aufbau der sozialen Welt, Springer.

/// Tansey J., O'Riordan T. 1999. Cultural Theory and Risk: A Review, "Health, Risk \& Society", vol. 1(1), pp. 71-90.

/// Terenzi P., Boccacin L., Prandini R., eds. 2016. Lessico della sociologia relazionale, il Mulino.

\section{/// Abstract}

Taking social relations into consideration allows us to be mindful of the life-world and the social system. A social relation should be intended as an emergent phenomenon of a mutual act, with an autonomous connotation that goes beyond those who implement it. At the same time, it can be traced back to referential semantics, as it exists within a framework of symbolic meaning, and to structural semantics, because it is at the same time a resource and a constraint for the social system. If these are the general foundations of the relational theory of society, adding risk to this perspective as a descriptive model has some distinguishing features. For example, as a dimension of everyday life it is a "neutral category." It is based on that "insecure security" whose results, positive or negative, will derive from the kind of balance established between "resources and challenges" or, as we claim in this paper, between "goals and means."

Keywords:

culture, morphogenesis, relational sociology, risk society 
/// Emiliana Mangone-associate professor of sociology of culture and communication at the Department of Human, Philosophical and Education Sciences of the University of Salerno (Italy). Since 2010, she has been associated with IRPPS-CNR of Rome (Institute for Research on Population and Social Policies) and she is a director of the International Centre for Studies and Research "Mediterranean Knowledge." She recently published (with Mohieddine Hadhri): Intercultural Complexity of the Southern Mediterranean: Arab-Mediterranean Perceptions and Outlooks in "Journal of Mediterranean Knowledge" (2016), Mediterranean Knowledge for the Future of Europe (2015).

E-mail: emangone@unisa.it 